59) Masing, E., Zur Anwendung der Lumbalpunktion bei Hirntumoren. Petersburger Medizinische Wochenschrift, 1904, No. 1.

Verf. weist auf Grund eines einschlägigen Falles auf die therapeutische Wertlosigkeit und die Gefährlichkeit der Lumbalpunktion bei Hirntumor hin.

C. Gutmann (Strassburg i. E.).

\title{
Uebersicht über wissenschaftliche Arbeiten betr. Krebsleiden, welche im Buchhandel erschienen oder in Fachzeitschriften veröffentlicht sind,
}

folgt in nächster Nummer.

Vermischtes.

In der letzten Sitzung des Komitees für Krebsforschung wurden die Herren Geheimer Medizinalrat Dr. A. Ba er-Berlin, Dr. W e rn erHeidelberg, Prof. Dr. Winter-Königsberg zu Mitgliedern des Komitees gewählt.

Die Bildung von Landeskomitees für Krebsforschung ist in verschiedenen Bundesstaaten in die Wege geleitet.

Die Errichtung eines Institutes für Krebsforschung in Heidelberg durch private Stiftung steht bevor.

Die Herren Kollegen werden $\mathrm{um}$ gefallige Einsendung ron Sonderabdricken ron Arbeiten sowie ron Ionographien iiber die Krebskrankheit gebeten, deren Inzeige bezw. Besprechung: in dieser Zeitschrift erfolgen wird. 